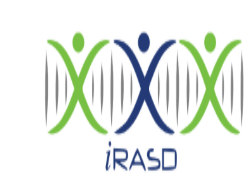

iRASD Journal of Management

Volume 3, Number 3, 2021, Pages 285 - 301

\title{
Linking Inventory Efficiency, Productivity and Responsiveness to Firm Performance in Pakistan
}

\author{
Mirha Mubarak ${ }^{1}$, Naila Sadiq ${ }^{2}$, Syeda Fizza Abbas ${ }^{3}$ \\ ${ }^{1}$ Scholar, Kinnaird College for Women Lahore, Pakistan, Email: mirha.mubarak04@gmail.com \\ ${ }^{2}$ Lecturer, Kinnaird College for Women Lahore, Pakistan, Email: naila.sadiq@kinnaird.edu.pk \\ ${ }^{3}$ Head of Department, Kinnaird College for Women Lahore, Pakistan, Email: fizza.abbas@kinnaird.edu.pk
}

\begin{tabular}{|c|c|}
\hline ARTICLE INFO & ABSTRACT \\
\hline $\begin{array}{ll}\text { Article History: } & \\
\text { Received: } & \text { November 30, } 2021 \\
\text { Revised: } & \text { December 28, 2021 } \\
\text { Accepted: } & \text { December 28, } 2021 \\
\text { Available Online: } & \text { December 29, } 2021\end{array}$ & $\begin{array}{l}\text { Inventory is one of the most important current assets of any } \\
\text { company, therefore, efficient usage and management of } \\
\text { inventory are necessary for the long-term success of any } \\
\text { business. This research links three main components of } \\
\text { inventory management i.e. efficiency, productivity, and }\end{array}$ \\
\hline $\begin{array}{l}\text { Keywords: } \\
\text { Pakistan, Chemical Sector } \\
\text { Inventory Efficiency } \\
\text { Inventory Productivity } \\
\text { Inventory Responsiveness } \\
\text { Financial Performance } \\
\text { Operational Performance }\end{array}$ & $\begin{array}{l}\text { operational and financial performance within the chemical } \\
\text { sector of Pakistan. For this purpose, ten years of data from } \\
2011-2020 \text { was collected from the annual financial statements } \\
\text { of } 21 \text { companies within the chemical sector to develop and } \\
\text { examine a panel data model. The regression analysis provides } \\
\text { strong evidence that both the inventory productivity and } \\
\text { responsiveness measures positively and significantly result in }\end{array}$ \\
\hline & $\begin{array}{l}\text { firm outperformance. However, the correlation test suggests } \\
\text { that there is a weak negative relationship between inventory } \\
\text { efficiency and firm performance while inventory productivity } \\
\text { has a strong positive correlation and inventory responsiveness } \\
\text { has a weak positive correlation with firm performance. The } \\
\text { research adds to the existing literature on inventory } \\
\text { management by utilizing new inventory control measures in } \\
\text { the context of a developing economy such as Pakistan. }\end{array}$ \\
\hline
\end{tabular}
article under the Creative Common Attribution Non-Commercial 4.0 Corresponding Author's Email: naila.sadiq@kinnaird.edu.pk

\section{Introduction}

Inventory is one of the most important current assets of any company, therefore, efficient usage and management of inventory are necessary for the long-term success of any business. However, inventory management becomes even more essential for retailing and manufacturing businesses that deal with a huge amount of inventory inflow, outflow and storage daily. Several research studies have been conducted in the past that have linked efficient inventory management to a higher firm operational performance in different countries throughout the world. Based on this foundation, the main aim of this research is to identify if there is any relationship between inventory management practices and company performance within the chemical industry of Pakistan.

With the ever-expanding consumption in our healthcare division, there's an immediate need to control this challenge while ensuring that accessible assets are utilized to supply basic drugs to the ever-increasing population of our country. Pharmacy departments are one of the foremost customers of the hospital budget and one of the few regions where a large amount of cash is going through on buying various medications, drugs, and chemicals. It is therefore important that healing centers guarantee a smooth supply of the specified stock to ensure continuous supply (Leaven, Ahmmad, \& Peebles, 2017). Most of these pharmaceutical companies receive their raw materials in the form of chemicals from the chemical firms in the market. This calls for the compelling stock 
administration of chemical stores inventory by keeping close supervision on vital drugs, avoidance of pilferage, and preference setting in buying and distribution of various chemicals and drugs.

A research paper by (Buschiazzo, Mula, \& Campuzano-Bolarin, 2020) was conducted on 21 healthcare centers in Spain. This paper proposed a simulation model for the inventory management problem in highly specialized medical institutions with complex supply chain systems. The analysis of the results led to a purchases plan that met demand during all the periods. Varying the total costs revealed the importance of suitable managing these parameters, like safety stock and capacity.

Inventory management can be defined as all the practices carried out to ensure that the customers are provided with the necessary goods and services. It brings together manufacturing, distribution, purchasing, and selling processes to fulfill the marketing as well as the company's needs of providing the final product to the end customer ( $T$. Li, Fang, \& Baykal-Gürsoy, 2021). It also involves specifying the size and placement of inventory items to multiple locations in the supply chain to guarantee a smooth flow of production. Moreover, by maintaining a balance of asset management, demand forecasting, inventory valuation, and quality management, it is possible to reach an optimal inventory level which will lead to the highest firm performance that will give companies a competitive advantage (Mishra, Wu, \& Sarkar, 2021).

In the past, the literature on inventory has usually highlighted production and procurement as the fundamental components of a firm's inventory management policies. However, in recent years there has been a drastic improvement in the category of operational management and many new techniques have emerged in the way inventory is controlled throughout the production process. These have been considered as more efficient inventory control procedures time and again and these practices include the Just in Time (JIT) system, Economic Order Quantity (EOQ) model, Material Requirement Planning System (MRP), and Enterprise Resource Planning (ERP) strategies whereas another developing course of research hypothesizes that the features of a firm's inadequate consumer demand inherent in these concepts and methods, ought to have an impact in firms' execution when applied in real trade life (Wang, Hou, \& Zhu, 2021).

\subsection{Problem Statement}

Over time industries have become more competitive with new businesses entering the market every day. Therefore, it has become essential for firms to benefit from lower average costs to gain a competitive advantage.

In addition to this, several real-world problems deteriorate the quality of many inventory items such as medicines, chemicals, blood banks, and other sensitive materials throughout the storage period. Factors like rust, rot, decay, spoilage, inadequacy, obsolescence, and evaporation reduce the useful life of inventory items making it a problem for inventory managers. Moreover, economic factors like inflation and the time value of money also affect different kinds of inventory products (Taleizadeh \& Nematollahi, 2014)

In a study of inventory management in Spain, it was estimated that the costs of purchasing healthcare supplies represented $25 \%$ of a hospital's total costs, which means it plays a big part in driving the profitability of companies and therefore requires proper attention (Buschiazzo et al., 2020). The biggest issue faced by any firm while managing its inventory is to be able to match its supply of products with the required demand in the market. Ideally, a firm wants to manufacture and maintain an adequate inventory level to satisfy the customers so that no sales are lost because of shortage of inventory but simultaneously, a firm does not want to hold too much inventory at hand due to the high storage and maintenance costs. Adequate but not extra levels of inventory are the main objective of any firm (HR \& Aithal, 2020).

Problems are most likely to occur when the operational management fails to track inventory properly because then supplies are lost, stock-outs occur, shrinkage can go unchecked and inventory on hand can increase unnecessarily. All these inventory issues can 
lead to higher costs and inefficiency which may cause adverse effects on the firm's overall performance.

Generally, the efficiency or inefficiency of inventory management is only one of the factors that affect company performance. There is a wide dimension of other macroeconomic factors as well on the firm level as well as the industry level which are equally important. In the past, researchers have worked on industry-level variables as well such as the Structure Conduct Performance SCP framework. This framework focuses on the impact of a company's market share and industry concentration since an increase in both of these elements has been linked with an increase in profitability. Another study has also investigated other possible determinants, such as strategic direction, size of the board, the ownership structure of the firm, product innovation, etc (Gołaś, 2020). However, to separate the effect of inventory management, other possible determinants of performance have not been inculcated in this study.

\subsection{Significance of Study}

This study will assist in identifying whether there is a significant relationship between the inventory practices of a firm and its performance within the chemical industry of Pakistan. The findings of this research can then be used as basic information by chemists, pharmacists, and inventory control staff to develop and introduce friendly and cost-efficient inventory policies for purchasing drugs and chemicals and controlling their levels as well so that they can gain maximum efficiency and productivity from their inventory management.

The research questions that will be studied in this paper that how inventory efficiency, productivity, and responsiveness affect the overall performance of the chemical firms in the industry.

\subsection{Research Objectives}

The summary research objective is to:

Empirically observe, test, and present a research model that creates a viable relationship between different elements of an organization's inventory control policies mainly efficiency, productivity, and responsiveness with the various performance measures to evaluate the effect of inventory management execution on the organization's competitive performance in the chemical sector of Pakistan.

\section{Literature Review}

The inventory management strategies differ across firms and sectors based on their respective stage in the product lifecycle and the introduction of new innovative products in different market segments and making a connection of those strategies with the firms' profitability has always been a difficult matter for many industry analysts, retailers, economists, and researchers. A US electronic retailer, Best Buy, introduced a new product strategy with a higher margin in the early 2000s in an attempt to target specific market groups. At the same time, it also invested in better inventory control technologies and partnered with various suppliers to improve its supply chain design and provide its customers with a wide variety of digital goods and services. Chain store retailers in the US such as Best Buy incur approximately $\$ 30$ billion on capital expenditure every year to improve their inventory management process (Fisher \& Raman, 2010) but still, retail firms have been unable to make much progress in obtaining high financial returns from these capital investments.

Furthermore, the impact of effective inventory control on performance is undefined in many sectors across different countries, for example, US retailing firms have high inventory stock out problems, high failure rates and weak customer services (Ayodele, Gbadebo, \& Dele, 2020). The extent to which stock administration policy is synchronized with other operational practices, product lifecycle stages, and particular techniques of fragment competitors will decide how a company's competitive position changes within the market as stock management tends to create competitive advantage in terms of costefficiency, reduced wastages, leaner production process, and increased profitability for a 
company in any sector (Jurado-Muñoz, Fernandez-Paredes, Quiroz-Flores, \& CardenasRengifo, 2021)

\subsection{Inventory Efficiency}

Some researchers through their extensive studies have found sufficient evidence that some industries as a whole have incurred better operating performance as a result of becoming leaner operationally and improving inventory efficiency (Westfall, Lister, Coulston, \& McRoberts, 2021).

Inventory efficiency measure has been used in several previous studies at a firm level on both quarterly and annual basis. Almost all of these studies have concluded a positive significant relationship between inventory efficiency measures and firm performance (Hu \& Shan, 2020). However, literature on retail management has faced challenges in creating a link between these measures and higher firm profitability over some time.

\subsection{Inventory Productivity}

Firms may react to competitive dangers by getting more effective and by contributing to supply chain investment that will offer assistance in overseeing modern product-driven complexities, extended product combinations, and product accessibility over their chain store systems (Z.-X. Li et al., 2018). When analyzing different inventory levels using gross margin return on investment as a measure for productivity, it is also required to adjust for the quarterly sales and the fixed assets across individual firms (Köksalmış, 2018).

Firms benefit the most from holding high extra stock when the linked or relevant items are more famous, have better control on pricing, have larger disposal value or have higher gross margin returns attached with them. However, few examinations have been carried out to explore empirical evidence on the relationship between competitive segments and firm profitability. Nevertheless, extent researchers have found that firms who have higher gross margin returns on inventory investment will turn out to have higher productivity with their inventory purchases and will therefore have superiority over their competitor firms in terms of productivity (Shockley \& Turner, 2015) (Lin, Liang, \& Zhu, 2018).

\subsection{Inventory Responsiveness}

Inventory responsiveness has been defined as the ability of an organization to balance its inventory production with the changes in the rapidly advancing market and fierce competitive conditions over time. It is directly linked to better firm performance in general.

The measures used to evaluate inventory responsiveness are dependent on both inventory management research models and primary analytical tools by comparing the flexibility of the supply of inventory with the cost of goods sold (Ikechukwu, 2019).

However, the measure of responsiveness used by these researchers provides a quarterly operational performance result. They also disclose that the yearly degree of responsiveness outcomes over retail and discount divisions don't compare with generally superior organizational level execution. This criterion has not been utilized to look at chemical firms particularly, nor their operating or financial performance measures.

\subsection{Economic Order Quantity Theory}

The theory of economic order quantity was initially introduced in 1913 by F. W. Haris and is regularly used by organizations to evaluate the optimal level of inventory that they should keep gaining a competitive advantage in terms of cost-efficiency. The EOQ curve helps in identifying a minimum point where the total inventory holding cost and ordering cost is the lowest (Battini, Calzavara, Isolan, Sgarbossa, \& Zangaro, 2018) 
The model requires that there is a need to identify the most cost-effective point of order for every item in the stores. The model assumes all other variables as constant even though uncertainties may exist in regular business processes such as change in demand, transportation damage and delay in delivery. Therefore, the EOQ model should be adjusted to buffer against uncertain business environment.

\subsection{Just In Time Approach}

Just In Time (JIT) is an inventory control technique which states that the inventory should be brought in and delivered out just at the time they are required so that the companies can avoid the huge holding costs associated with inventory. JIT method was initially introduced by Japanese firms who made their production processes leaner and more efficient through this strategy. For this model to work efficiently there are certain prerequisites that a firm must meet before applying this strategy. These conditions include having a very strong communication flow with the suppliers so that they are informed promptly of the need for raw materials. The transportation channel must also be very smooth so that any transportation delays can be avoided. Proper training of employees and a reliable sales forecasting system are also essential for JIT to work (Mukwakungu, Mabasa, Mankazana, Mzileni, \& Burakeye, 2019).

There is great potential in the implementation of JIT in Pakistani firms especially in times of economic distress such as the current Covid-19 situation as it assists in minimizing the inventory of raw materials, work in progress, and finished goods which would ultimately lead to lower average costs of production.

\subsection{The Operations Literature on Inventory Management}

The theoretical literature on inventory management in terms of operational research is full of many optimization models which are based on all aspects of inventory such as planning, production, delivery, and supply chain system. These proposed OR literature models are implemented by many logistic managers especially in commercial software firms (Gallino, Moreno, \& Stamatopoulos, 2017). Researchers have observed that a firm's total cost comprises of various cost elements such as inventory holding and delivery and only the optimization of a part of these cost elements will result in optimal decisions for firm performance and supply chain model (Glock, Grosse, Jaber, \& Smunt, 2019)). OR studies hardly evaluate the comparison between different inventory types such as raw materials, work in progress, and finished goods inventory, their only aim is to find optimal inventory cost solutions.

\subsection{The Economics Literature on Inventory Management}

Many economists have recognized the role of inventory in various business cycles but most of these studies have only focused on finished goods inventory and have failed to differentiate inventory types at different stages of the production process which is a major limitation in their studies to justify the behavior of a rational profit-maximizing organization (Glock et al., 2019). Therefore, the economic literature on inventory management provides substantial proof against using inventory as a single large entity.

Majorities of the published literature on inventory practices have concluded mixed findings and focused on finding empirical evidence from developed countries only but research on the impact of effective inventory control and firm performance was conducted in Egypt as a developing country. This study revealed that both these variables were positively correlated (Elsayed, Mohamed, \& Mohammed, 2015)

\subsection{Firm Performance}

\subsubsection{Financial Performance}

The financial performance of any firm is generally analyzed through its profitability ratios in the past because they are the most effective measure of how well the management is doing in terms of its investment and financing decisions. Therefore, anyone who is interested in the long-term economic survival of a firm will evaluate these ratios 
(Kopecká, 2018)Return on Assets (ROA) has been used as an explanatory dependent variable to identify the link between financial performance and inventory management in this study.

\subsection{Operational Performance}

Considering that interior components at organizations are fundamentally accountable for variations in performance, firms are anticipated to form relevant changes and improvements based on best policies to their basic and infrastructural components in an attempt to accomplish chosen productivity and profitability objectives (B. Lessing, 2021; J. Lessing, 2021). Making adequate changes in their operational practices according to the advancements in the market is what leads to outstanding operational performance for any organization. New manufacturing and inventory control technologies such as Total Quality Management techniques, Just In time inventory control, Outsourcing, and ISO Certification may have positive effects on a firm's operational performance (Albuhisi \& Abdallah, 2018)

Moreover, the same researcher evaluated the effect of TQM on the overall performance of the organization and found out that there exists a direct positive relationship between TQM and productional efficiency, however, no significant relationship was found with market performance or financial performance variables (Albuhisi \& Abdallah, 2018)

In another survey of semiconductor supply chain models, it was observed that demand forecasting, capacity planning, and supply chain revisions and improvements created a positive impact on overall inventory management and control (Mönch, Uzsoy, \& Fowler, 2018)

In this study Return on Sales (ROS) has been used as a measure to evaluate the operational efficiency of the firms in the chemical industry. This variable provides an insight into how much profit is being generated per rupee of sales.

\subsection{Conceptual Framework}

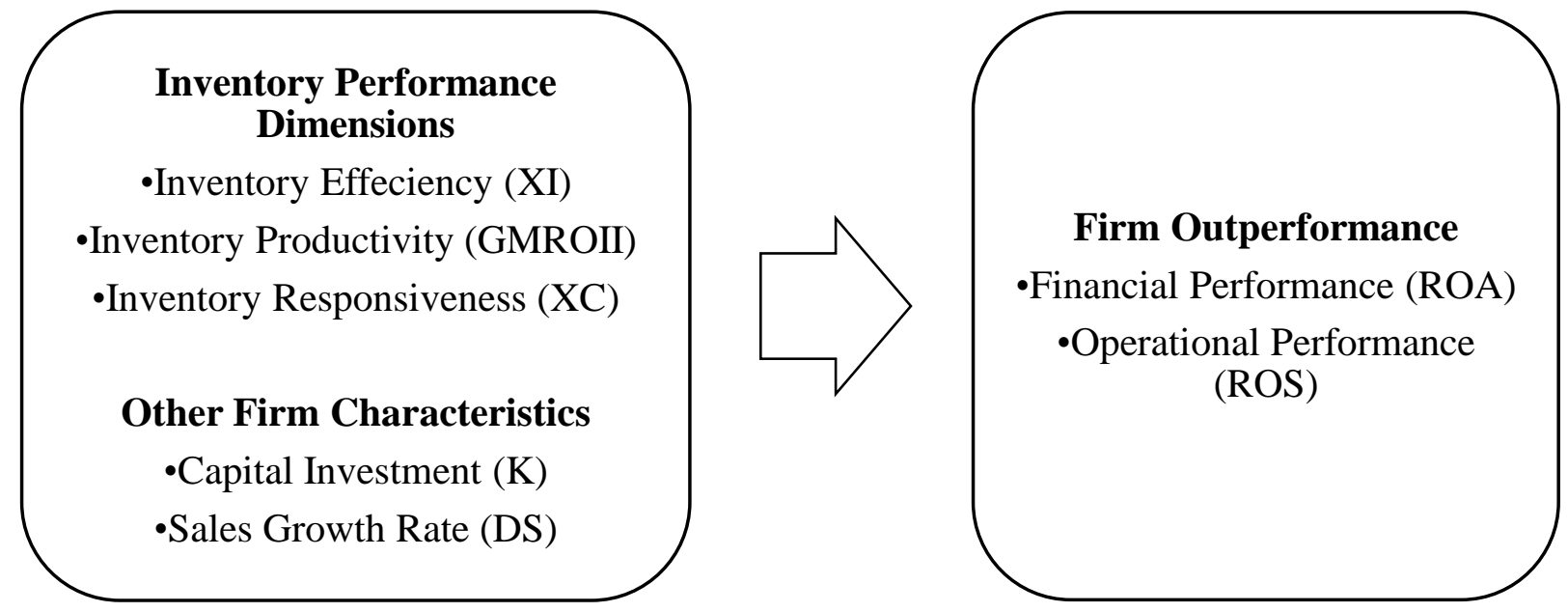

Figure 1 Theoretical Framework

3. RESEARCH METHODOLOGY

\subsection{Data}


Secondary financial data was collected directly from the annual financial reports of the companies in the chemical sector through the official KSE data portal and OpenDoors.pk website. The data were obtained for ten years from 2011 to 2020 from the annual consolidated financial statements. There are 25 companies listed under the chemical sector of the Pakistan Stock Exchange. Four companies from this sample were defaulters so they have been completely omitted from the sample group. The final sample consisted of 21 companies and an unbalanced panel data of 205 observations were collected.

\section{Table 1.}

\section{Years of complete data for each company}

\begin{tabular}{llll}
\hline ID & COMPANY NAME & YEARS OF DATA & NO. OF OBSERVATIONS \\
\hline 1 & Agritech Limited & $2011-2019$ & 9 \\
2 & Archroma Pakistan Limited & $2011-2020$ & 10 \\
3 & Berger Paints Pakistan Limited & $2011-2020$ & 10 \\
4 & Biafo Industries Limited & $2011-2020$ & 10 \\
5 & Buxly Paints Limited & $2011-2020$ & 10 \\
6 & Colgate Palmolive Pakistan Limited & $2011-2020$ & 10 \\
7 & Data Agro Limited & $2011-2019$ & 9 \\
8 & Descon Oxychem Limited & $2011-2020$ & 10 \\
9 & Dynea Pakistan Limited & $2011-2020$ & 10 \\
10 & Engro Polymer and Chemical Limited & $2011-2019$ & 9 \\
11 & ICI Pakistan Limited & $2011-2020$ & 10 \\
12 & Ittehad Chemicals Limited & $2011-2020$ & 10 \\
13 & Lotte Chemical Pakistan Limited & $2011-2019$ & 9 \\
14 & Leiner Pak Gelatine Limited & $2011-2020$ & 10 \\
15 & Nimir Industrial Chemicals Limited & $2011-2020$ & 10 \\
16 & Nimir Resins Limited & $2011-2020$ & 10 \\
17 & Pakistan Oxygen Limited & $2011-2019$ & 9 \\
18 & Sardar Chemical Industries Limited & $2011-2020$ & 10 \\
19 & Sitara Chemical Industries Limited & $2011-2020$ & 10 \\
20 & Sitara Peroxide Limited & $2011-2020$ & 10 \\
21 & Wah Noble Chemicals Limited & $2011-2020$ & 10 \\
Total Observations= & & 205 \\
\hline
\end{tabular}

\subsection{Statistical Tools and Techniques}

SPSS 25 was used to analyze the descriptive and normality tests among the collected data. SPSS 25 and STATA13 both have been used to test all the other assumptions and tests before running the panel data regression. Panel data regression analysis is being used to collect and compare the results of the previous years as well to identify the trend pattern of inventory variables followed by chemical companies with time. Previous researchers such as (Shockley \& Turner, 2015) have also used a fixed-effects panel regression model in their studies related to inventory management. STATA13 was used to run the Hausman test and the Random Effects panel regression analysis was used to test whether all the research hypotheses are being accepted or rejected.

$$
P R_{i t}=\mu_{i}+b_{1} X_{i t}+b_{2} G M R O I I_{i t}+b_{3} X C_{i t}+b_{4} K_{i t}+b_{5} D S_{i t}
$$

where $i$ is the value of that firm for the year $t_{1} \mu_{i}$ is the error value for the firms; the dependent variable performance PERFit measured through the ROA and ROS performance ratios of the firms for that particular year; $b^{1}, b^{2}$, and $b^{3}$ represent the coefficients for the inventory management performance measures which are XI, GMROII, and XC; $b^{4}$ and $b^{5}$ are the coefficients for the control variables capital investment $\mathrm{K}$ and sales growth rate DS.

\subsection{Hypothesis Formulation}

> $\mathrm{H} 1=$

$\mathrm{H}_{0}$ : There is no significant effect of Inventory efficiency $\left(\mathrm{XI}_{\mathrm{it}}\right)$ on firm performance

$\mathrm{H}_{1}$ : There is a significant effect of Inventory efficiency $\left(\mathrm{XI}_{\text {it }}\right)$ on firm performance

\section{- $\mathrm{H}_{2}=$}

$\mathrm{H}_{0}$ : There is no significant effect of Gross margin return on inventory investment (GMROII ${ }_{i t}$ ) on firm performance 
$\mathrm{H}_{1}$ : There is a significant effect of Gross margin return on inventory investment (GMROII ${ }_{\text {it }}$ ) on firm performance

- $\mathrm{H}_{3}=$

$\mathrm{H}_{0}$ : There is no significant effect of Inventory responsiveness $\left(X C_{i t}\right)$ on firm performance

$\mathrm{H}_{1}$ : There is a significant effect of Inventory responsiveness $\left(X C_{i t}\right)$ on firm performance

Table 2

Variables \& Measurements

\begin{tabular}{llc}
\hline $\begin{array}{l}\text { Variable Type and Name } \\
\text { Dependent Variables }\end{array}$ & Measurement & Supportive Literature \\
\hline Return on Assets & ROA= Earnings before tax (EBT) / & (Nawaz, Hamid, Khurram, \& \\
& Total Assets (TA) & Nawaz, 2016) \\
& & (Shockley \& Turner, 2015) \\
(Farooq, 2019)
\end{tabular}

Return on Sales

Independent Variables

Inventory Efficiency (Avg

Inventory/ COGS ratio)

Inventory Productivity (Gross Margin Return on

Inventory Investment)

Inventory Responsiveness

(Co-movements of Inventory and COGS)

Control Variables

Capital Investment

Sales Growth Rate

ROS = Earnings before tax (EBT) / Net Sales (S)

(Shockley \& Turner, 2015)

$\mathrm{XI}_{\mathrm{it}}=$ Average Inventory $\left(\mathrm{Inv}_{\mathrm{it}}\right) /$ Cost of Goods Sold (COGS it )

$\mathrm{GMROII}_{\mathrm{it}}=$ Gross Margin $\left(\mathrm{GM}_{\mathrm{it}}\right) /$

Average Inventory ( $\operatorname{Inv}_{\mathrm{it}}$ )

$\mathrm{XC}_{\mathrm{it}}=\left[\left(\operatorname{Inv}_{\mathrm{it}}-\operatorname{Inv}_{\mathrm{i}(\mathrm{t}-1)}\right) / \operatorname{Inv}_{\mathrm{i}(\mathrm{t}-1)}\right]-[$

$\left(\right.$ COGS $\left.\left._{i t}-\operatorname{COGS}_{i(t-1)}\right) / \operatorname{COGS}_{i(t-1)}\right]$

$K_{i t}=\log \left(P P E_{i t}\right)$

$D S_{i t}=\left[\left(S_{i t}-S_{i(t-1)}\right)\right] / S_{i(t-1)}$
(Shockley \& Turner, 2015)

(Shockley \& Turner, 2015)

(Shockley \& Turner, 2015)

(Shockley \& Turner, 2015)

(Shockley \& Turner, 2015)

(Farooq, 2019)

\section{Results}

\subsection{Descriptive Statistics}

Table 3

Descriptive Statistics

\begin{tabular}{|c|c|c|c|c|c|c|c|c|c|}
\hline \multirow[b]{2}{*}{ ROA } & \multirow{2}{*}{$\frac{\text { Statistic }}{205}$} & \multirow{2}{*}{$\begin{array}{l}\text { Min } \\
\text { Statistic } \\
-.24\end{array}$} & \multirow{2}{*}{$\begin{array}{c}\begin{array}{c}\text { Max } \\
\text { Statistic }\end{array} \\
.46\end{array}$} & \multirow{2}{*}{$\begin{array}{c}\begin{array}{c}\text { Mean } \\
\text { Statistic }\end{array} \\
.0868\end{array}$} & \multirow{2}{*}{$\begin{array}{c}\begin{array}{c}\text { Std } \\
\text { Statistic }\end{array} \\
.11546\end{array}$} & \multicolumn{2}{|c|}{$\begin{array}{l}\text { Skewness } \\
\text { Statistic Std }\end{array}$} & \multicolumn{2}{|c|}{$\begin{array}{c}\text { Kurtosis } \\
\text { Statistic Std }\end{array}$} \\
\hline & & & & & & .839 & .170 & .891 & .338 \\
\hline ROS & 205 & -1.84 & .42 & .0392 & .21856 & -4.912 & .170 & 34.039 & .338 \\
\hline PERF & 205 & -1.95 & .86 & .1260 & .30174 & -2.354 & .170 & 13.850 & .338 \\
\hline XI & 205 & .03 & .51 & .1863 & .09622 & .840 & .170 & .609 & .338 \\
\hline GMROII & 205 & -3.40 & 16.82 & 1.8484 & 2.16685 & 3.873 & .170 & 23.268 & .338 \\
\hline XC & 205 & -1.06 & 2.25 & .0892 & .45393 & 1.464 & .170 & 4.389 & .338 \\
\hline $\mathrm{K}$ & 205 & 5.66 & 10.78 & 9.0609 & .90819 & -.700 & .170 & 1.008 & .338 \\
\hline DS & 205 & -.60 & 1.69 & .1165 & .25439 & 1.850 & .170 & 9.084 & .338 \\
\hline Valid N & 205 & & & & & & & & \\
\hline
\end{tabular}

Table 3 shows the various descriptive statistics of the variables. The average return on assets of the companies working in the chemical study is 0.0868 whereas the average return on sales is 0.0392 . This means that chemical companies are doing much better in terms of financial profitability as compared to operational profitability. The mean values of all our independent variables are also positive. Such inventory efficiency measure has a mean value of 0.1863 ranging from 0.03 to 0.51 . The average gross margin return on inventory investment is 1.8484 but its range is very high i.e from -3.4 to 16.82 which means that this measure varies extensively from one company to another within the industry. The average inventory responsiveness is 0.0892 ranging from -1.06 to 2.25 .

The value of skewness shows the length of the distribution pattern or lack of symmetry within it while the kurtosis value depicts the peak or the height of the distribution curve. Ideally, a bell-shaped curve should have a skewness and kurtosis value equal to zero. The skewness values of XI, GMROII, XC, and DS are all greater than zero so it can be 
said that their distributions are positively skewed, while the variables PERF and $\mathrm{K}$ have skewness values less than zero, so their distributions are negatively skewed. On the other hand, the kurtosis values of all the variables are greater than zero so they are highly peaked with more data values close to the center of the distribution.

\subsection{Normality of Dependent Variable}

The normality of the dependent variable PERF is checked by constructing a Histogram and tested by carrying out the Kolmogrov Smirnov and Shapiro Wilk normality tests.

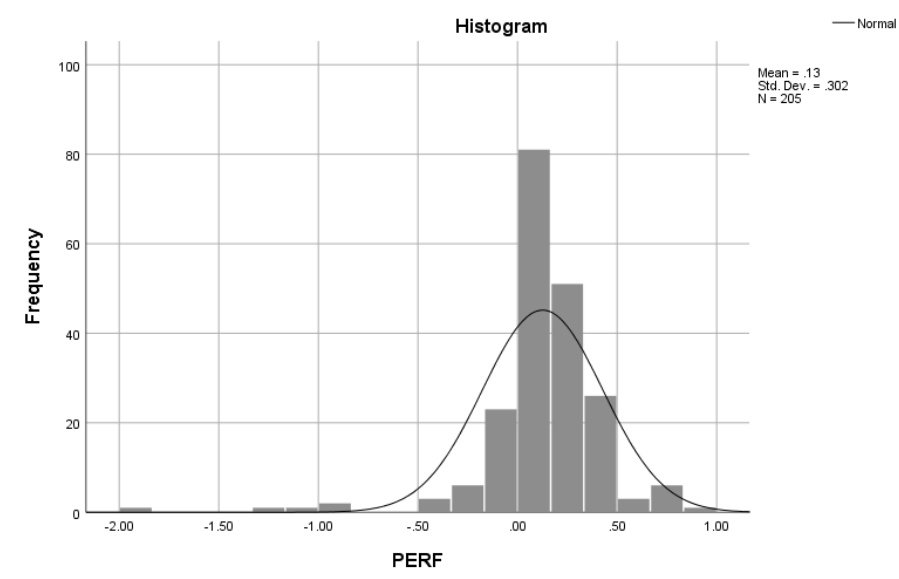

Figure 2 Normality Histogram Before

Through the histogram above it can be observed that the dependent variable PERF has an asymmetric pattern that is slightly negatively skewed towards the left side hence depicting a non-normal distribution of values.

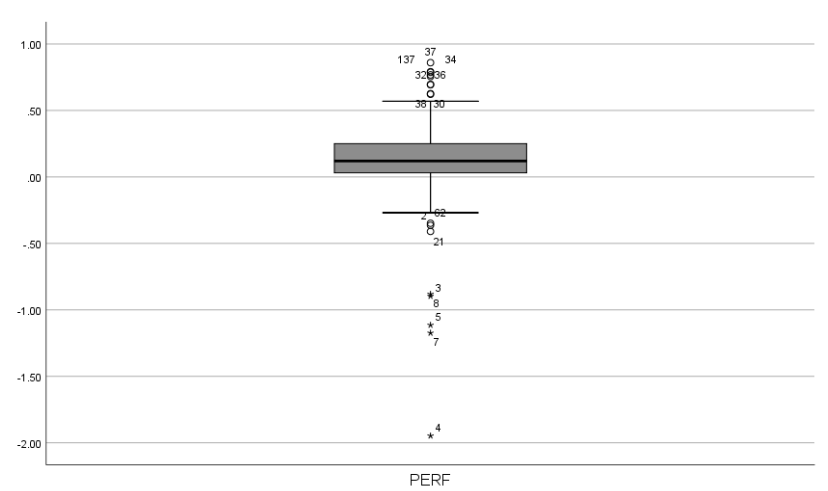

Figure 3 Boxplot Before

Moreover, even the boxplot shows numerous values lying outside the interquartile range and these outliers are in both positive and negative directions suggesting that the distribution is not normal.

Table 4

Normality Test Before

\begin{tabular}{lllllll}
\hline & \multicolumn{3}{l}{ Kolmogorov Smirnov } & \multicolumn{3}{l}{ Shapiro Wilk } \\
& Statistic & Df & Sig. & Statistic & Df & Sig. \\
\hline PERF & .163 & 205 & .000 & .797 & 205 & .000 \\
\hline
\end{tabular}

$\mathrm{H}_{0}$ : The sample data follows a normal distribution

$\mathrm{H}_{1}$ : The sample data does not follow a normal distribution

Since the P-value of both KS and SW tests is 0.000 which is less than the $a=0.05$, so we reject $\mathrm{H}_{0}$ and conclude that the population of PERF follows a non-normal distribution. 
To achieve normality of the dependent variable, the variable PERF was then fractional ranked and a new normalized variable NPERF was generated by using the idf. normal function in SPSS.

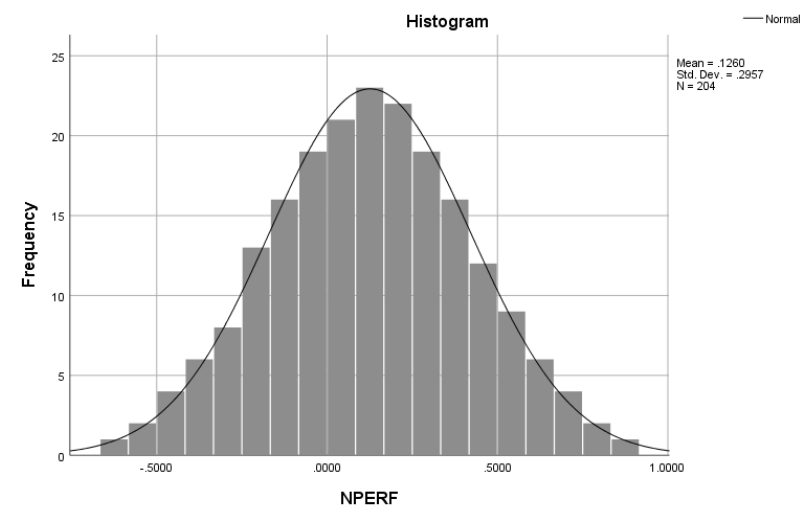

Figure 4 Normality Histogram After

As we can see from the histogram above the new NPERF variable has a bell-shaped symmetric distribution pattern which shows that the data is normal, but we will further conduct the normality tests as well to double-check.

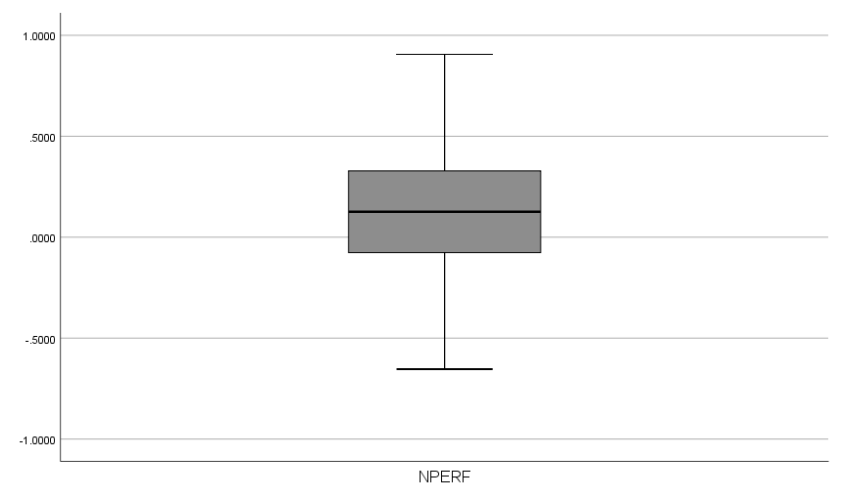

Figure 5 Boxplot After

Moreover, even the boxplot above shows a normal pattern with most values centered around the median and between the interquartile range.

\section{Table 5}

Normality Test After

\begin{tabular}{lllllll}
\hline & \multicolumn{3}{l}{ Kolmogorov Smirnov } & \multicolumn{4}{l}{ Shapiro Wilk } \\
& Statistic & Df & Sig. & Statistic & Df & Sig. \\
\hline NPERF & .006 & 204 & $.200^{*}$ & .999 & 204 & 1.000 \\
\hline
\end{tabular}

$\mathrm{H}_{0}$ : The sample data follows a normal distribution

$\mathrm{H}_{1}$ : The sample data does not follow a normal distribution

Since the KS and SW test values are greater than $a=0.05$ so we do not reject $\mathrm{H}_{0}$ and conclude that the population from which the sample was taken does follow a normal distribution hence, now the results will not be biased due to outliers. 


\subsection{Correlation Matrix}

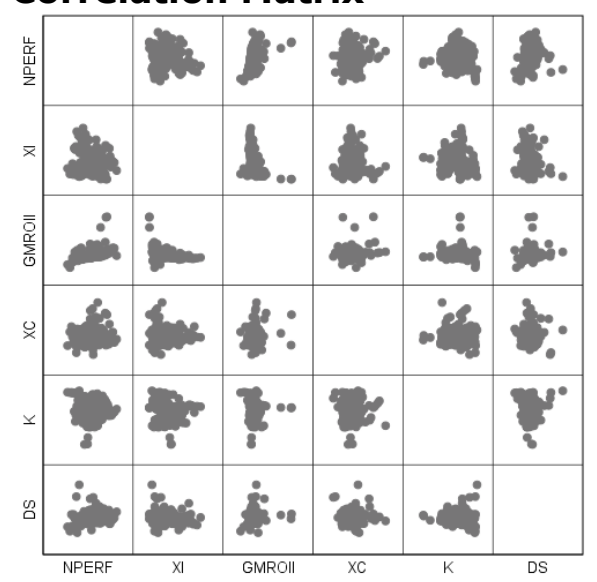

Figure 6 Matrix Plot

Linearity between the independent and dependent variable is checked by constructing a correlation matrix plot and tested through the coefficient of correlation through linearity tests.

Examining the matrix plot it can be said that the independent variable Inventory Productivity (GMROII) is positively linearly correlated with the dependent variable Performance (NPERF) whereas the independent variable Inventory Efficiency (XI) is negatively correlated with the dependent variable Performance (NPERF). However, the variable Inventory Responsiveness (XC) seems to be in a random unidentified linear pattern with NPERF. Therefore, we will further conduct pairwise correlation tests to conclude whether linearity exists or not.

\subsection{Linearity Tests}

Table 6

Correlations

\begin{tabular}{lllllll}
\hline & NPERF & XI & GMROII & XC & K & DS \\
\hline NPERF & 1 & & & & & \\
XI & -0.1476 & 1 & & & & \\
GMROII & 0.4405 & -0.4302 & 1 & & & \\
XC & 0.0915 & -0.0445 & 0.1541 & 1 & 1 & \\
K & -0.0635 & -0.2609 & 0.0056 & 0.0096 & 0.0258 & 1 \\
DS & 0.1826 & -0.1551 & 0.1708 & -0.0597 & 0 \\
\hline
\end{tabular}

The table above shows the pairwise correlations among the different variables in my study generated through Stata. The Pairwise Correlation coefficient is the measure of the strength of linear correlation where we determine the correlation percentage between our dependent and independent variables. This value determines the extent to which the variables move by each other as a linear pattern. From the table, we can observe that XI is negatively correlated with our dependent variable NPERF because its value is less than 0 , whereas GMROII is strongly positively correlated with our NPERF. After all, its value is around 0.5 , and the linear strength between GMROII and NPERF is $44.05 \%$. On the other hand, XC is also positively correlated with NPERF but it is weak because the value of their correlation is between 0 to 0.3 and the strength of their correlation is $9.15 \%$.

\subsection{Multicollinearity}

If various independent variables are linearly related, they are said to have multicollinearity. Ideally, there should not be multicollinearity among the independent variables which means that they should not have linear dependence on each other. As the values of Variance Inflation Factor (VIF) are less than 10, so all these independent variables are linearly independent and hence it can be concluded that multicollinearity does not exist in my data set. 
Table 7

VIF table

\begin{tabular}{lll}
\hline Variable & VIF & $\mathbf{1 / V I F}$ \\
\hline KI & 7.06 & 0.141736 \\
XI & 4.87 & 0.205155 \\
GMROII & 2.08 & 0.481896 \\
DS & 1.26 & 0.795827 \\
XC & 1.07 & 0.931025 \\
Mean VIF & 3.27 & \\
\hline
\end{tabular}

\subsection{Auto Correlation}

\section{Table 8}

Wooldridge test

$\mathrm{F}(1,20)$

Prob $>\mathrm{F}$

Autocorrelation measures the relationship between the present values and the past values of a variable. Ideally, there should not be autocorrelation in the data set, however, as the $p$-value of our Wooldridge test results, 0.000 is less than the $a=0.05$ so we reject $\mathrm{H}_{0}$ and conclude that there is autocorrelation in the data set.

\subsection{Heteroskedasticity}

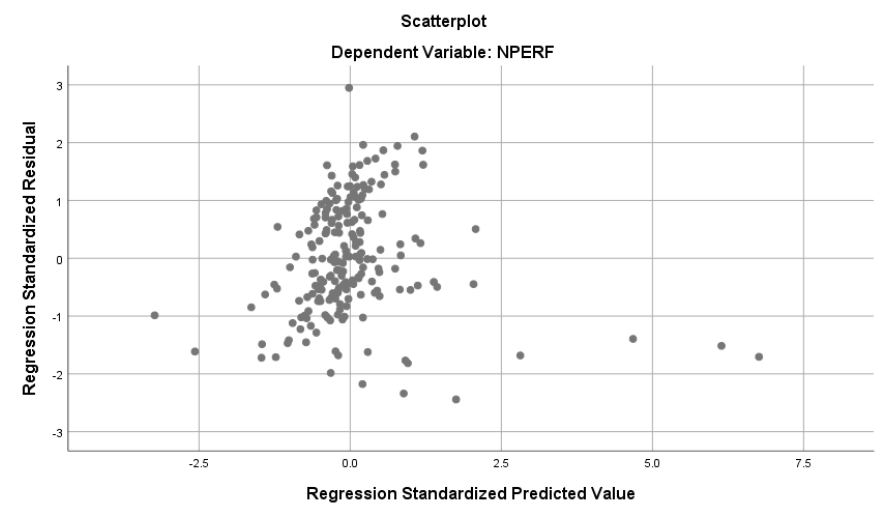

Figure 7 Scatter Plot of Residuals

One of the assumptions of regression is that the data set must be homoscedastic which means that it should have constant variances while its opposite is heteroskedasticity which suggests that the data does not have equal variances. By observing the scatter plot of residuals above we can identify a specific outward opening funnel pattern which means that the residuals do not have equal variances. Considering this, we can say that heteroskedasticity does exist in my data set. However, to double-check the Breusch Pagan test for random effects was also conducted.

\section{Table 9}

\section{Breusch-Pagan Test}

\begin{tabular}{lll}
\hline & Var & Sd = sqrt(Var) \\
\hline NPERF & 0.000 & 257176 \\
E & 0.000 & 137257 \\
U & 0.000 & 248886 \\
Chibar2 $=$ & 4542 & \\
Prob $>$ chibar2 $=$ & 0.000 &
\end{tabular}

$\mathrm{H}_{0}$ : Data is homoscedastic

$\mathrm{H}_{1}$ : Data is heteroskedastic

Since the significance value of Breusch Pagan test is 0.000 which is less than $a=0.05$ so we reject $\mathrm{H}_{0}$ and conclude that the data follows heteroskedasticity. 
Since the assumptions of autocorrelation and heteroskedasticity have not been achieved so the VCE (robust) command was used with the final regression model which accommodates for both heteroskedasticity and autocorrelation. This command works by robustifying the standard errors.

\subsection{Regression Analysis}

In a panel data analysis, the Hausman test assists in choosing between a fixed effects model or a random effects model.

\section{Table 10}

\section{Hausman Test}

chi2 1.00

Prob > chi2

0.9626

$\mathrm{H}_{0}$ : The preferred model is random effects

$\mathrm{H}_{1}$ : The preferred model is fixed effects

Since the p-value is greater than 0.05 so we accept the null hypothesis and conclude that the random effects model is more appropriate for this study. As the random effects model is preferred for this study so we will only report and interpret the findings of this particular regression model.

\section{Table 11}

\begin{tabular}{|c|c|c|c|c|}
\hline NPERF & Coeff. & Robust Std. Err. & $\mathbf{Z}$ & $P>[z]$ \\
\hline XI & 0.01415 & 0.3287 & 0.04 & 0.966 \\
\hline GMROII & 0.06336 & 0.0103 & 0.09 & 0.000 \\
\hline$x C$ & 0.04540 & 0.0151 & 3.00 & 0.003 \\
\hline K & 0.00554 & 0.0228 & 0.24 & 0.808 \\
\hline DS & 0.14620 & 0.0700 & 2.09 & 0.037 \\
\hline Cons & -0.06494 & 0.2302 & -0.28 & 0.778 \\
\hline \multicolumn{5}{|c|}{ Model Diagnostics } \\
\hline \multirow[t]{2}{*}{ R-square } & Within & Between & Overall & \\
\hline & 0.4126 & 0.1183 & 0.2048 & \\
\hline
\end{tabular}

$R$ square is the coefficient of determination and denotes the percentage of effect of the independent variables together on the dependent variable. In this model $\mathrm{R}$ Square= 0.2048 which means that $20.48 \%$ variation in NPERF is justified by its relationship with Inventory Efficiency (XI), Inventory Productivity (GMROII), and Inventory Responsiveness $(\mathrm{XC})$.

As the $\mathrm{P}$ values of Inventory Productivity (GMROII) and Inventory Responsiveness (XC) are both less than the $a=0.05$, so it is concluded that both these independent variables have a significant positive influence on Firm Performance (NPERF). Whereas the measure of Inventory Efficiency (XI) also has a positive coefficient suggesting a positive relationship but the $p$-value is greater than the $a=0.05$ so its impact on the firm performance is not significant enough.

\section{Discussion}

From the results of Table 13 presented above it can be observed that the coefficient of gross margin return on inventory investment is 0.06336 which means that an increase in inventory productivity would lead to an increase of approximately $6.3 \%$ in the performance of the business. While the coefficient of responsiveness is 0.04540 which means that it would lead to an increase of approximately $4.5 \%$ in the overall performance of the business keeping the effect of all other variables constant.

This random effect model shows strong support for our second and third hypotheses, but the first alternate hypothesis could not be accepted. This could be due to various underlying reasons such as the measure used to determine inventory efficiency was not appropriate for a developing country like Pakistan. Moreover, generally, researchers use 
inventory turnover ratio to measure inventory efficiency, however, since this study obtained its background of the theoretical framework from the work of (Shockley \& Turner, 2015), this measure in the model could not be changed or removed as it could affect the overall results of the study.

The results from this study align with the literature on inventory management and past researches of (Nyabwanga \& Ojera, 2012; Ogbo \& Ukpere, 2014; Shockley \& Turner, 2015), and (Elsayed et al., 2015) all of which concluded a significant impact of various inventory control measures on the overall performance. Moreover, the insignificant result of inventory efficiency is directly in alignment with the study of (Farooq, 2019) who studied the impact of inventory efficiency measure in the context of 79 Pakistani non-financial firms from cement, sugar, and automobile sectors from 2006 to 2015 and through GMM regression concluded that there was an insignificant impact of inventory turnover ratio on $\mathrm{ROA}, \mathrm{ROE}$, and net profit margin.

Moreover, (Nawaz et al., 2016) also conducted a study on the effect of inventory performance measures on the non-financial firms in Pakistan from 2010 to 2014 and concluded through correlation tests that inventory turnover had a weak positive relationship with ROA and ROE and the GLM regression showed an insignificant impact of inventory turnover on ROA. Furthermore, the result of a negative correlation between inventory efficiency and performance is supported by the studies of (Z.-X. Li et al., 2018; Shockley \& Turner, 2015).

The results show that both productivity and responsiveness can be identified as having a strong positive relationship with the overall performance of a firm so they must be inculcated as important factors when setting up inventory control policies. Another observation we can deduct from the model is that Gross Margin Return on Inventory Investment is the strongest measure among the three in driving the overall performance of the firm higher as its linear correlation and regression coefficient values are the highest. Therefore, companies must take measures to improve this ratio as much as they can. One way they can do this is by stocking less of their poor-selling inventory, rather, they should stock more of the products that sell quickly so that their gross margin can improve. Furthermore, chemical firms should ensure that all their inventory records are kept accurately and improve their inventory responsiveness by making sure that the right amounts of inventory are held by the firms at all times.

On the other hand, it must also be kept in mind that inventory control policies are not one size fits all which means they cannot be suitable for use by all companies in all kinds of situations, rather, they may depend from one sector to another and from one time period to another. Therefore, management should inculcate all the surrounding external factors as well before making any prominent changes in their inventory policies. Since many researchers in Pakistan have had difficulty in associating the significant impact of inventory turnover on organizational performance so more focus should be given to the productivity and responsiveness aspects of inventory control because they lead to a significant change (Farooq, 2019).

This kind of exploratory study is a beginning point for more detailed research in the behavior of inventory practices within firms that belong to different sectors as (Shockley \& Turner, 2015) also concluded in their study that results of inventory measures are segment-specific. For policymakers and analysts in the chemical sector, this study can be of immense importance as it may help them in developing a deeper knowledge and understanding of the many advantages associated with a leaner operation process. By using the theoretical framework presented in this research as a foundation, firms can deduce competitive policies regarding the way they manage their inventories.

\section{Conclusion}

This study has been conducted in Pakistan which is a developing economy and therefore adds to the existing literature through the contribution of Pakistani chemical firms. The model used in this report to assess the relationship between inventory management measures and overall firm performance provides sufficient evidence that both the inventory control measures of inventory productivity and inventory responsiveness 
positively and significantly impact the operational as well as the financial performance of companies in the chemical industry.

As a result of the discussion and the conclusion above it is advised that companies should take continuous actions to improve their gross margin return on inventory investment and the inventory responsiveness ratio as it will help the company achieve productivity and profitability in terms of inventory which will ultimately provide the company with a competitive advantage. Firms should strive towards achieving leanness in their inventory production and storage by investing in better and modern inventory control technologies to stay up to date with the industrial competitiveness by achieving cost advantages. Firms are also suggested to work towards improving the rate at which they respond to customer demand with their levels of inventory as it can also lead to an increase in the profitability of the firms. The objective should be to maintain an optimum level of inventory that does not lead to over-responsiveness or under-responsiveness.

\subsection{Recommendations}

The following steps can be taken by researchers in their future studies to further thoroughly understand the relationship between inventory practices and company performance:

Sample size can be increased by inculcating companies from other sectors as well such as the pharmaceutical sector.

The longitudinal period can be increased by collecting data of the past fifteen or twenty years. Other control factors such as Relative gross margin rate, Sales over fixed assets ratio, or Debt to assets ratio can be used to see their impact on the overall model fit. The impact of Covid-19 on inventory practices and company performance can be examined.

Regional Analysis of the chemical sector for inventory practices can be done during and post Covid-19.

\subsection{Limitations}

The study only includes the chemical sector of the market therefore its results can only be associated with and utilized by chemical manufacturing companies specifically. This means that analysts and decision-makers belonging from other sectors may not be able to fully benefit from its findings.

A few years of data for some companies has been omitted from the final panel due to the unavailability of data. Only three control factors are used for this study.

\section{References}

Albuhisi, A. M., \& Abdallah, A. B. (2018). The impact of soft TQM on financial performance: The mediating roles of non-financial balanced scorecard perspectives. International Journal of Quality \& Reliability Management.

Ayodele, O., Gbadebo, W., \& Dele, T. (2020). Impact of Inventory Management Practices on the Financial Health of Small Scale Manufacturing Enterprises. ADEDIPE, Oluwaseyi Ayodele OLADEJI, Ige Olubunmi, 73.

Battini, D., Calzavara, M., Isolan, I., Sgarbossa, F., \& Zangaro, F. (2018). Sustainability in material purchasing: A multi-objective economic order quantity model under carbon trading. Sustainability, 10(12), 4438.

Buschiazzo, M., Mula, J., \& Campuzano-Bolarin, F. (2020). Simulation optimization for the inventory management of healthcare supplies. International Journal of Simulation Modelling, 19(2), 255266.

Elsayed, A. T., Mohamed, A. A., \& Mohammed, O. A. (2015). DC microgrids and distribution systems: An overview. Electric power systems research, 119, 407-417. 
Farooq, U. (2019). Impact of inventory turnover on the profitability of non-financial sector firms in Pakistan. Journal of Finance and Accounting Research, 1(1), 34-51.

Fisher, M., \& Raman, A. (2010). The new science of retailing: how analytics are transforming the supply chain and improving performance: Harvard Business Review Press.

Gallino, S., Moreno, A., \& Stamatopoulos, I. (2017). Channel integration, sales dispersion, and inventory management. Management Science, 63(9), 2813-2831.

Glock, C. H., Grosse, E. H., Jaber, M. Y., \& Smunt, T. L. (2019). Applications of learning curves in production and operations management: A systematic literature review. Computers \& Industrial Engineering, 131, 422-441.

Gołaś, Z. (2020). Does Inventory Management Improve Profitability? Empirical Evidence from Polish Manufacturing Industries. European Research Studies, 23(2), 939-961.

HR, G., \& Aithal, P. (2020). Integrated Inventory Management Control Framework. International Journal of Management, Technology, and Social Sciences (IJMTS), 5(1), 147-157.

Hu, Y., \& Shan, J. (2020). Supplier-Based Concentration and Inventory Efficiency. International Journal of Information Systems and Supply Chain Management (IIISSCM), 13(4), 95-113.

Ikechukwu, A. J. (2019). Assessment of organizational performance of private manufacturing companies: the impact of supply chain management responsiveness. Journal of System and Management Sciences, 9(3), 26-44.

Jurado-Muñoz, N., Fernandez-Paredes, I., Quiroz-Flores, J., \& Cardenas-Rengifo, L. (2021). Lean Inventory Management Model to Reduce Defective Products in Peruvian Baking SMEs. Paper presented at the 2021 10th International Conference on Industrial Technology and Management (ICITM).

Köksalmış, G. H. (2018). AERONAUTICS AND SPACE TECHNOLOGIES'INVENTORY EFFICIENCY, INVENTORY PRODUCTIVITY AND INVENTORY RESPONSIVENESS VS. FINANCIAL PERFORMANCE. Journal of Aeronautics and Space Technologies, 11(1), 65-74.

Kopecká, N. (2018). A literature review of financial performance measures and value relevance. The Impact of Globalization on International Finance and Accounting, 385-393.

Leaven, L., Ahmmad, K., \& Peebles, D. (2017). Inventory management applications for healthcare supply chains. Int. J. Supply Chain Manag, 6(3), 1-7.

Lessing, B. (2021). Conceptualizing criminal governance. Perspectives on Politics, 19(3), 854-873.

Lessing, J. (2021). Analysing the effect of inventory management on operational performance in a manufacturing environment. North-West University (South Africa),

Li, T., Fang, W., \& Baykal-Gürsoy, M. (2021). Two-stage inventory management with financing under demand updates. International Journal of Production Economics, 232, 107915.

Li, Z.-X., Zhu, Q.-N., Zhang, H.-B., Hu, Y., Wang, G., \& Zhu, Y.-S. (2018). MALAT1: a potential biomarker in cancer. Cancer management and research, 10, 6757.

Lin, Y., Liang, B., \& Zhu, X. (2018). The effect of inventory performance on product quality: The mediating effect of financial performance. International Journal of Quality \& Reliability Management.

Mishra, U., Wu, J.-Z., \& Sarkar, B. (2021). Optimum sustainable inventory management with backorder and deterioration under controllable carbon emissions. Journal of Cleaner Production, 279, 123699.

Mönch, L., Uzsoy, R., \& Fowler, J. W. (2018). A survey of semiconductor supply chain models part I: semiconductor supply chains, strategic network design, and supply chain simulation. International Journal of Production Research, 56(13), 4524-4545.

Mukwakungu, S. C., Mabasa, M. D., Mankazana, S., Mzileni, X., \& Burakeye, S. A. (2019). The Impact of Just in Time (JIT) in Inventory Management-Perspectives from Two Case Studies in a South African Environment. Paper presented at the Proceedings of the International Conference on Industrial Engineering and Operations Management.

Nawaz, A., Hamid, K., Khurram, M. U., \& Nawaz, M. A. (2016). Impact of Inventory Performance on Industrial Financial Performance of Pakistan. International Journal of Multidisciplinary Approach and Studies, 3(6), 32-14. 
Nyabwanga, R. N., \& Ojera, P. (2012). Inventory management practices and business performance for small-scale enterprises in Kenya. KCA Journal of Business Management, 4(1), 11-28.

Ogbo, A. I., \& Ukpere, W. I. (2014). The impact of effective inventory control management on organisational performance: A study of 7up bottling company nile mile enugu, nigeria. Mediterranean Journal of Social Sciences, 5(10), 109-109.

Shockley, J., \& Turner, T. (2015). Linking inventory efficiency, productivity and responsiveness to retail firm outperformance: empirical insights from US retailing segments. Production Planning \& Control, 26(5), 393-406.

Taleizadeh, A. A., \& Nematollahi, M. (2014). An inventory control problem for deteriorating items with back-ordering and financial considerations. Applied Mathematical Modelling, 38(1), 93-109.

Wang, J., Hou, K., \& Zhu, X. (2021). Does sticky inventory management improve productivity? Journal of Manufacturing Technology Management.

Westfall, J. A., Lister, A. J., Coulston, J. W., \& McRoberts, R. E. (2021). Realized and potential efficiency for post-stratified estimation in a national forest inventory. Canadian Journal of Forest Research, 51(10), 1450-1457. 